\title{
Seasonal and Annual Meteorological Drought Frequency: Case Study West Hararge Province (Zone)
}

\author{
Abdisa Hirko ${ }^{1}$, Gezehagn Mergia ${ }^{1}$, Asalifewu Nigussie ${ }^{1}$, Tilahun Dandesa ${ }^{2} *$ \\ ${ }^{I}$ National Meteorology Agency of Ethiopia Eastern and Central Oromia Meteorological Services Centre, \\ Adama, Ethiopia \\ ${ }^{2}$ Oromia Bureau of Agriculture and Natural Resource, Addis Ababa, Ethiopia
}

*Corresponding Authors: Tilahun Dandesa, Oromia Bureau of Agriculture and Natural Resource, Addis Ababa, Ethiopia

\begin{abstract}
Over the years, the issue of drought has topped the agenda discussed at most climate change conferences and panels. Specifically, of ten times the negative impact of drought cannot be completely measured since drought affects both natural habitat and livelihood of an area. Drought is the manifestation of climate change and a common phenomenon in Ethiopia. Ethiopia faces widespread droughts, causing large economic and social damages. According to Segele and Lumb (2005), Ethiopia has been ravaged by severe drought for many of the last 35 years, primarily due to the failure of its main (kiremt) rainy season. This study attempts to identify the spatio temporal dynamics of Meteorological drought in West Hararge within 1990-2018. It employs the use of GeoCLIM of CHRIPS datasets. The CHIRPS dataset and the GeoCLIM tool were used to estimate SPI for the seasonal and annual Meteorological Drought. So we used Pixels and Image Resolution of CHIRPS pixel $=0.05$ degrees $\sim 5 \mathrm{~km}$. Spatial rainfall average and CV was identified annually. Meteorological drought reclassified into three classes Very Severe (extreme), moderate and Slight (mild) drought. The finding intended to identify frequency and magnitude of events.
\end{abstract}

Twenty (20yrs) Slight-Very severe drought events occurred in the period 1990-2018 in the province of West Hararge. The most important events were in the 2002, $2009 \& 2015$ 's, (all reached the very severe threshold). During the study periods annual drought event were $68.97 \%$ while no drought event were $31.03 \%$. The seasonal drought contribution to the study area is kiremt (40.42\%), Belg (31.92\%) and Bega (27.66\%). Annual drought tendency were very severe, slight and moderate drought with the magnitude of $15 \%, 50 \%$ and $35 \%$ respectively. Probability of recurrence on the category were slight, moderate and very severe drought on number of time in years 10, 7 and 3 and the magnitudes of severity of events 2 in $2 y$ rs, 1 in $3 y$ rs and 1 in $7 y$ rs respectively.

Generally, the entire study area can be considered as frequently meteorological drought prone area. Increasing tendencies and frequency of drought were observed during recent year (Figure 5 and Graph1.1, $1.2 \&$ Table 1.2, $1.3 \&$ 1.5). The finding shows that in the first decade (1990-1999) the annual magnitude of drought tendency were slight to moderate, whereas in the second decade (2000-2009) were under slight ,moderate and very severe and at the third decade (2010-2018) were under slight, moderate, and very severe categories. The seasonal magnitude of drought tendency increase both kiremt and belg during the second decade (1999-2009) (Figure5, Graph1.1, 1.2 \& Table 1.2, 1.3, 1.4, 1.5 and 1.6), and this shows that there is an increasing of drought frequency and tendency. The patterns of drought events in the study area are highly localized.

Keywords: Drought, Frequency, SPI, GeoCLIM

\section{INTRODUCTION}

Droughts are regional in nature and often characterized by temporary departures from normal precipitation resulting in severe water shortage. Drought is a natural and recurring feature of climate, which occurs in virtually all climate regimes. Impacts of droughts are multifaceted, affecting water resources (Shiau, 2006), agriculture (Wang, 2005), ecosystems (Reichstein et al., 2002) as well as socioeconomic aspects (Bardsley et al., 1984). Therefore, drought management and monitoring is an important issue (Wilhite, 1996).

Drought is a disastrous natural phenomenon that has significant impact on agricultural, environment and socio-economic conditions of the community. The concept of drought varies among regions of 
differing climates (Dracup et al., 1980) and resource base. In general, drought gives an impression of water scarcity resulted from insufficient precipitation, high Evapotranspiration, and over-exploitation of water resources or combination of these parameters.

Drought is the manifestation of climate change and a common phenomenon in Ethiopia. Ethiopia faces widespread droughts, causing large economic and social damages. According to Segele and Lumb (2005), Ethiopia has been ravaged by severe drought for many of the last 35 years, primarily due to the failure of its main (kiremt) rainy season. The agricultural sector on which 85 percent of the population depends is by far the largest sector being affected by drought. In dry land semi-arid areas, the major factors that aggravate the impact of drought are poor water management and hence agricultural production is below the potential. Generally, significant deficiency of precipitation from normal over an extended period of time results in plant water stress or agricultural drought in dry land semi-arid areas where most part of East and West Hararge is situated.

\subsection{Types of Drought}

Drought is a normal and recurrent feature of climate. It occurs virtually in all climatic zones, but its characteristics vary significantly from one region to another. According to Wilhite and Glantz (1985), drought can be classified on sectoral basis as follows:

\subsubsection{Meteorological Drought}

Meteorological drought refers to a deficiency of precipitation, as compared to average conditions, over an extended period of time. It basically originates from the deficiency of precipitation and focuses on the physical characteristics of drought (Mokhtari, 2005) rather than impacts associated with shortage of precipitation. Meteorological drought leads to a depletion of soil moisture and has always an impact on crop production.

\subsubsection{Agricultural Drought}

Agricultural drought is defined by a reduction in soil moisture availability below the optimal level required by a crop during the different growth stages, resulting in impaired growth and reduced yields. It is typically occurred after meteorological drought but before hydrological drought (Flood and Climate Basics, 2004). This drought does not depend only on the amount of rainfall but also the correct use of that water.

\subsubsection{Hydrological Drought}

Hydrological drought results when precipitation deficiencies begin to reduce the availability of natural and artificial surface and subsurface water resources. It occurs when there is substantial deficit in surface runoff below normal conditions or when there is a depletion of ground water recharge.

\subsubsection{Socio-Economic Drought}

Socio-economic drought occurs when human activities are affected by reduced precipitation and related water availability. This form of drought associates human activities with elements of meteorological, agricultural, and hydrological drought.

\section{SCOPE OF THE STUDY}

All areas are a complex and vast for all provinces in Ethiopia that could not do in one simple paper and the same is true to assess all drought types. For this reason; the scope of the study delimited on annual and seasonal Meteorological drought frequency of using GeoCLIM to analysis and interpret its strength, frequency, and distribution over West Hararge province. The study only used GeoCLIM dataset due to uneven long year station data over the parts of study area (Figure 1)

\section{OBJECTIVE OF THE STUDY}

The main objective of the study is to identify Frequency of Meteorological Drought

To analyses Seasonal and annual Meteorological Drought frequency over study area

To identify strength, frequency, recent and past Meteorological drought frequency and magnitude

\section{STUdy ARea}

West Hararge is among the eighteen provinces in Oromia regional state, Ethiopia which are situated in the Eastern part of the region. The average annual rainfall ranges between $525 \mathrm{~mm}$ and $1,100 \mathrm{~mm}$, with considerable spatial and temporal variability in quantities and distribution. The average annual temperature ranges between $13^{\circ}$ to $28^{\circ} \mathrm{C}$ and is characterized by erratic rainfall and recurrent failure of crops. Besides, in recent years the frequency of rain failures has increased in most of the woreda, 
especially in lowland areas. West Hararge zone is geographically located between $7^{0} 52^{1} 15^{11}$ $9^{0} 28^{1} 43^{11}$ North Latitude and $40^{0} 03^{1} 33^{11}-40^{0} 34^{1} 13^{11}$ East Longitudes. Attitudinally, the zone rises from nearly $600 \mathrm{~m}$.a.s.1 in the rift valley escarpment to 3080 M.a.s.l in the chercher highland(figure 1 \& 2). The zone is bounded by east Shewa and Arsi zone in the West, Bale zone in the south, East Hararge from the East Somali regional state in the north. The capital of the zone is Chiro Town which is located at a distance of $326 \mathrm{Km}$ from Finfine (Addis Ababa) and the total area of the West Hararge Zone is $17535 \mathrm{~km}^{2}$. Sources (West Hararge Socio-economic office).

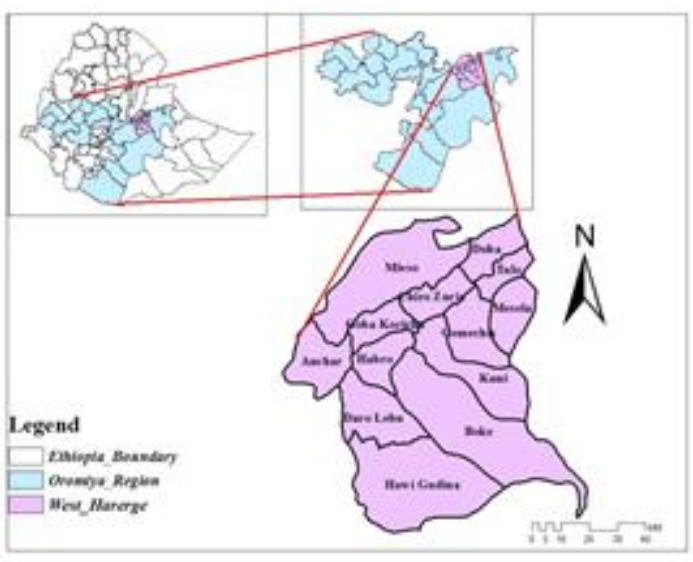

Figure1. Studv area Location

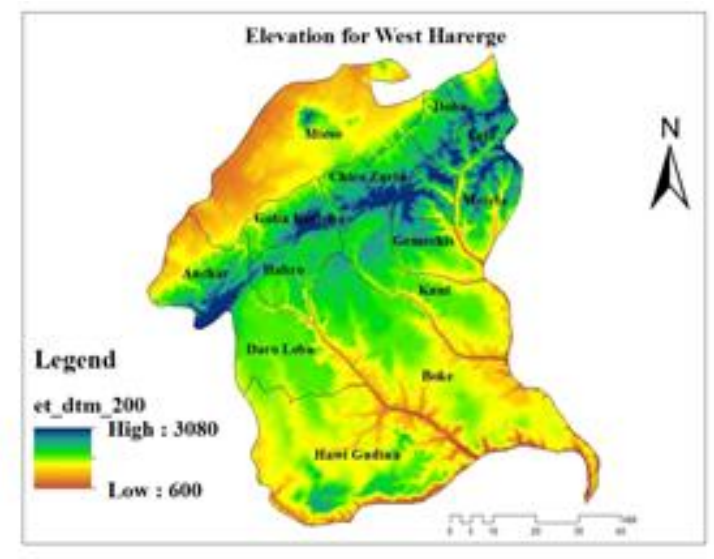

Figure2. West Harerge Province Elevation.

\section{Data AND Methodology}

Drought events result from a prolonged lack of precipitation. Depending on the timescale of these dry periods, they have impact on different water resources: meteorological conditions and agriculture area affected by relatively short timescales, while stream flows and reservoirs start to be affected by precipitation anomalies longer than 6-12 months. GeoCLIM Tool used to analyses SPI and account for this temporal variation of the dry periods, and to better investigate its magnitude and frequency. Its calculation depends on the seasonal and annual precipitation record from a specific location. This study is fitted to analyses the drought frequency seasonally and annually, so positive (negative) values of SPI indicate values greater (less) than the median precipitation across the location. The greatest strength of this index is the ability to quantify precipitation anomalies in multiple timescales assessing different hazards such as meteorological droughts (1-2 months).

Drought events are divided into four categories according to SPI values: Very severe drought (extreme) $($ SPI $\leq-2.00)$, Severe drought $(-1.50>$ SPI $>-1.99)$, Moderate drought $(-1.00>$ SPI $>-1.49)$ and Slight drought $(0>$ SPI $>-0.99)$.

Table1.1. Drought Severity Class.

\begin{tabular}{|l|l|}
\hline SPI Value & Drought Severity Class \\
\hline Above 0 & No drought \\
\hline 0.0 to -0.99 & Slight drought \\
\hline-1.0 to -1.49 & Moderate drought \\
\hline-1.5 to -1.99 & Severe drought \\
\hline-2 and less & Very severe drought \\
\hline
\end{tabular}

\section{DAta AnAlysis AND RESUlt}

The analysis with inputs of GeoCLIM Tool using Chirps Rainfall data mentioned below on (figure 3, 4 \& 5) was done to identify Seasonal and annual Meteorological drought frequency and CV over the province.

GeoCLIM can be used to evaluate and visualize trends in climate over recent historical periods and to assess the magnitude of projected changes (drought) in climate. Thus, within the participatory process it may be used in:

- assessing the situation

\section{- GeoCLIM Highlights}


- Blend station information with satellite data to create improved datasets

- Analyze seasonal trends and/or historical climate data

- Analyze drought for a selected region by calculating the standardized precipitation index

\subsection{Overview of GeoCLIM}

The GeoCLIM is a program designed for climatological analysis of historical rainfall and temperature data. The GeoCLIM provides non-scientists with an array of accessible analysis tools for climatesmart agricultural development. These user-friendly tools can be used to obtain and analyse climate data, blend station data with satellite data to create more accurate datasets, analyse seasonal trends and/or historical climate data, create visual representations of climate data, create scripts (batch files) to quickly and efficiently analyse similar "batches" of climate data, view and/or edit shape files and raster files, and extract statistics from raster datasets to create time series.

The CHIRPS dataset and the GeoCLIM tool were used to estimate SPI for the months, seasonal and annual. Spatial rainfall average was obtained for every year for each of the Hot spots identified. So we used Pixels and Image Resolution of CHIRPS pixel $=0.05$ degrees $\sim 5 \mathrm{~km}$.

\section{i. Pixels and Image Resolution}

- Pixels are different sizes e.g.

- CHIRPS pixel $=0.05$ degrees $\sim 5 \mathrm{~km}$

- $\quad$ ETa pixel $=1 \mathrm{~km}$

- $\quad$ eMODIS NDVI pixel $=250 \mathrm{~m}$

- The smaller the pixel, the finer the image, the more spatial information is in the image, and the closer you can zoom into the image

- Images with smaller pixels are said to have higher resolution

\subsection{Standard Precipitation Index (SPI) Computation with GeoCLIM Tool}

SPI was designed to quantify the rainfall deficit for multiple timescales in the studied area using GeoCLIM Tool used CHIRPS data and we used CHIRPS pixel $=0.05$ degrees $\sim 5 \mathrm{~km}$. The SPI is a $\mathrm{z}-$ score and represents the drought event departure from the mean, expressed in standard deviation units. SPI is a normalized index in time and space. This feature allows comparisons of SPI values among different locations. Although SPI can be calculated from 1 month up to 72 months, 1-24 months is the best practical range of application (Guttman, 1999; WMO, 2012). We, therefore, computed the SPI values at 3-12 months or Seasonal \&annual (SPI 3-12). The SPI 3-12 was used to assess droughts which used to assess the seasonal and annual drought. Positive SPI values indicated greater than mean rainfall and negative values indicated less than mean rainfall.

\subsection{Annual Average Rainfall and CV for West Hararge from 1990-2018 years}
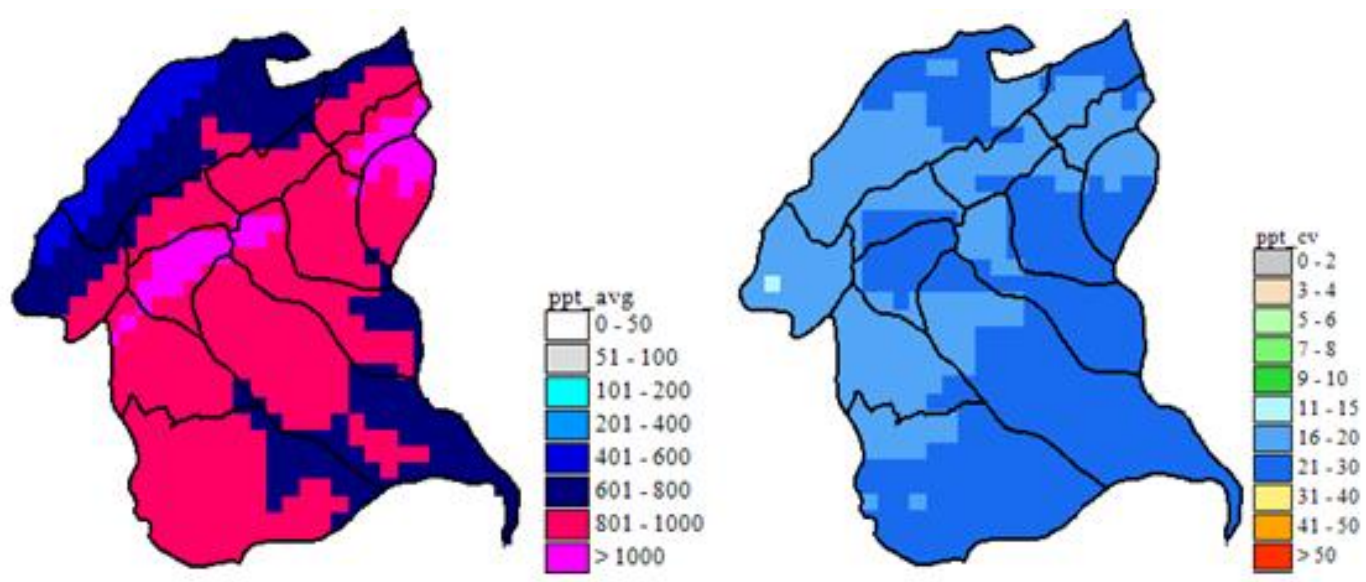

The maximum average rainfall is over Highland whereas minimum average is over lowland of the study area. CV is in the range of moderate threshold over the study area (Figure $3 \& 4$ ). 


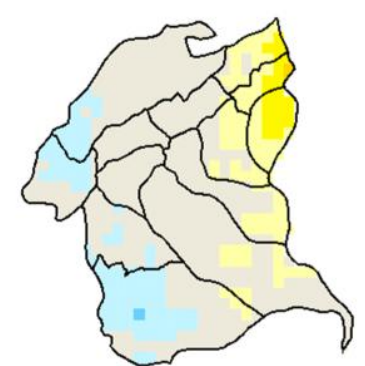

Annual SPI_1991

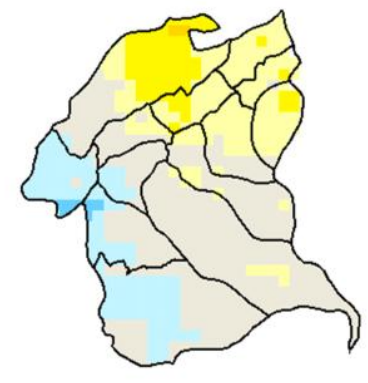

Annual SPI_1992

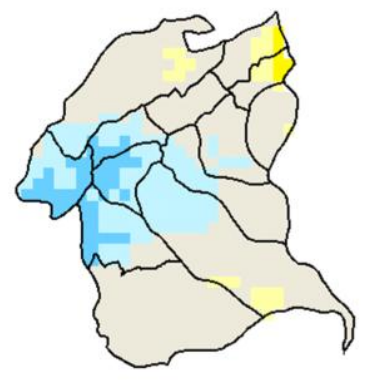

Annual SPI_1994

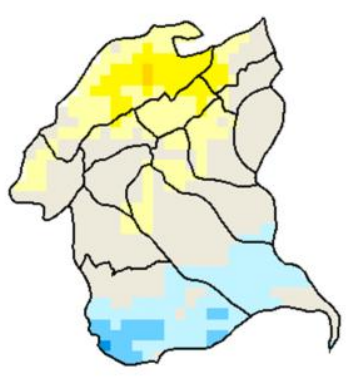

Annual SPI_1995
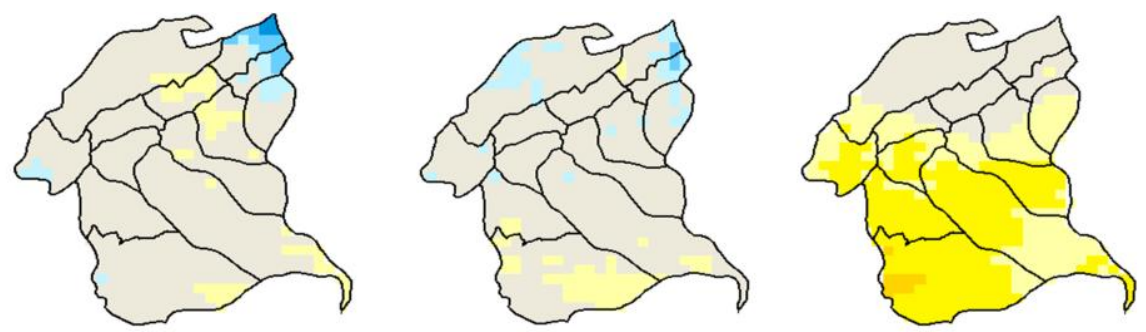

Annual SPI_1999
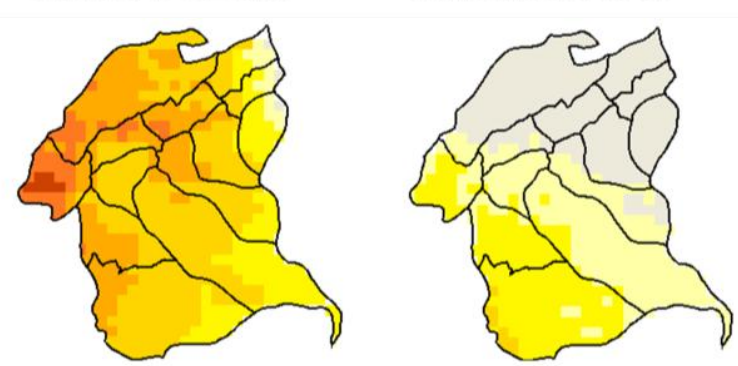

Annual SPI_2000
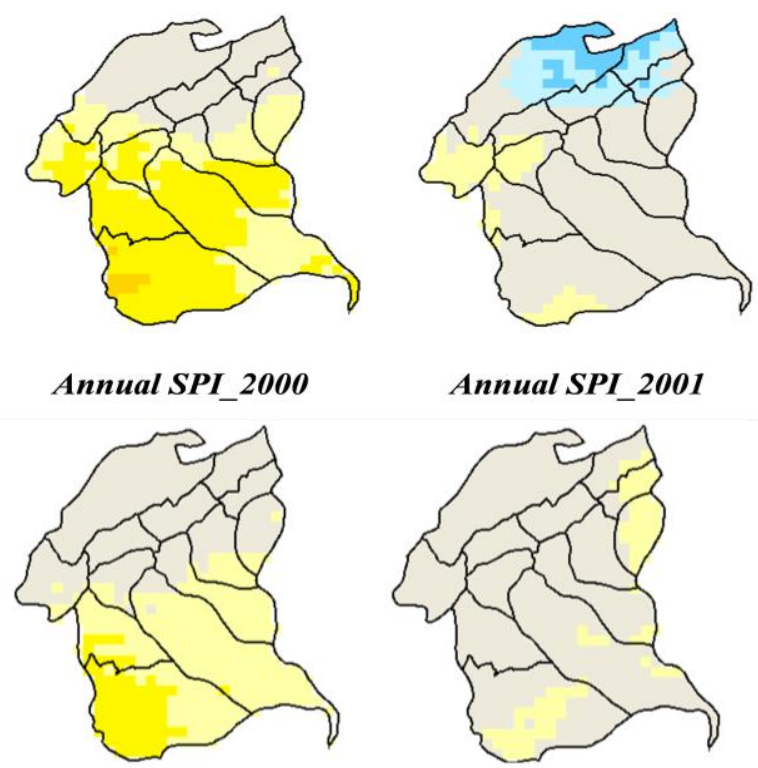

Annual SPI_2003

Annual SPI_2004

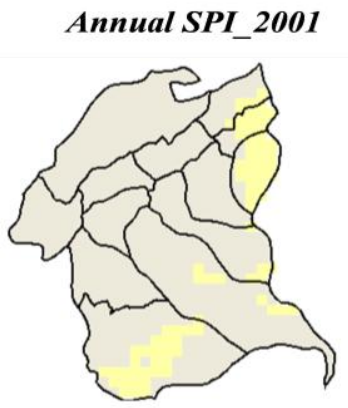

Annual SPI_2002
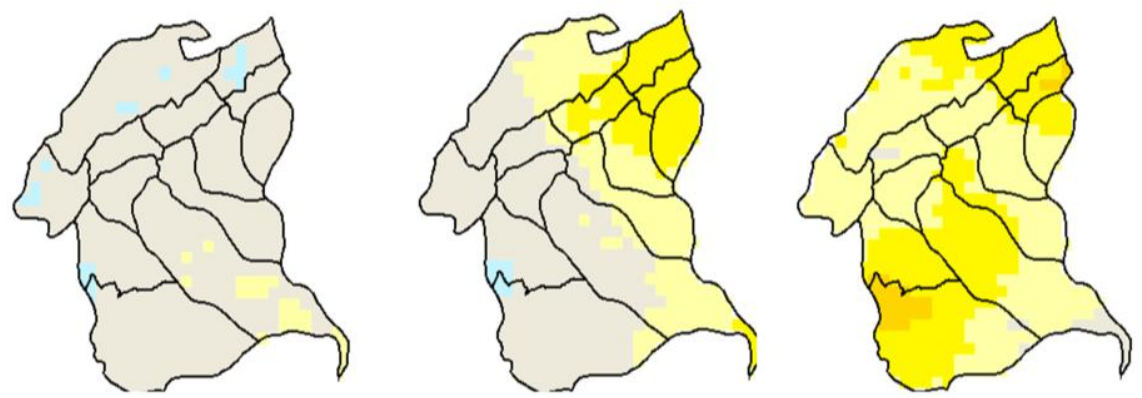

Annual SPI_2005

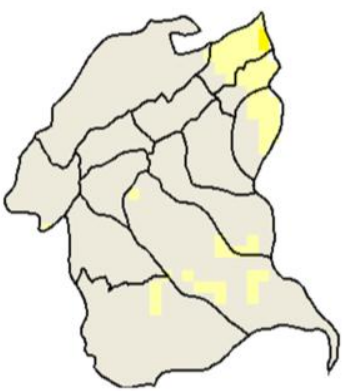

Annual SPI_2011

Annual SPI_2007

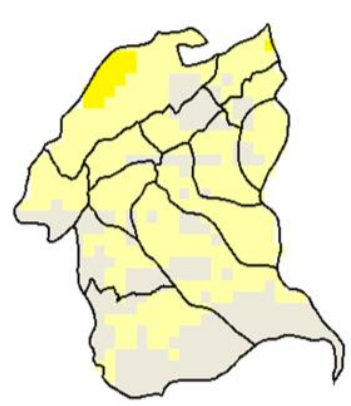

Annual SPI 2012

Annual SPI_2008

Annual SPI_2009

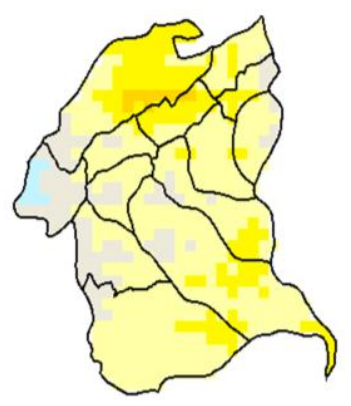

Annual SPI_2017 


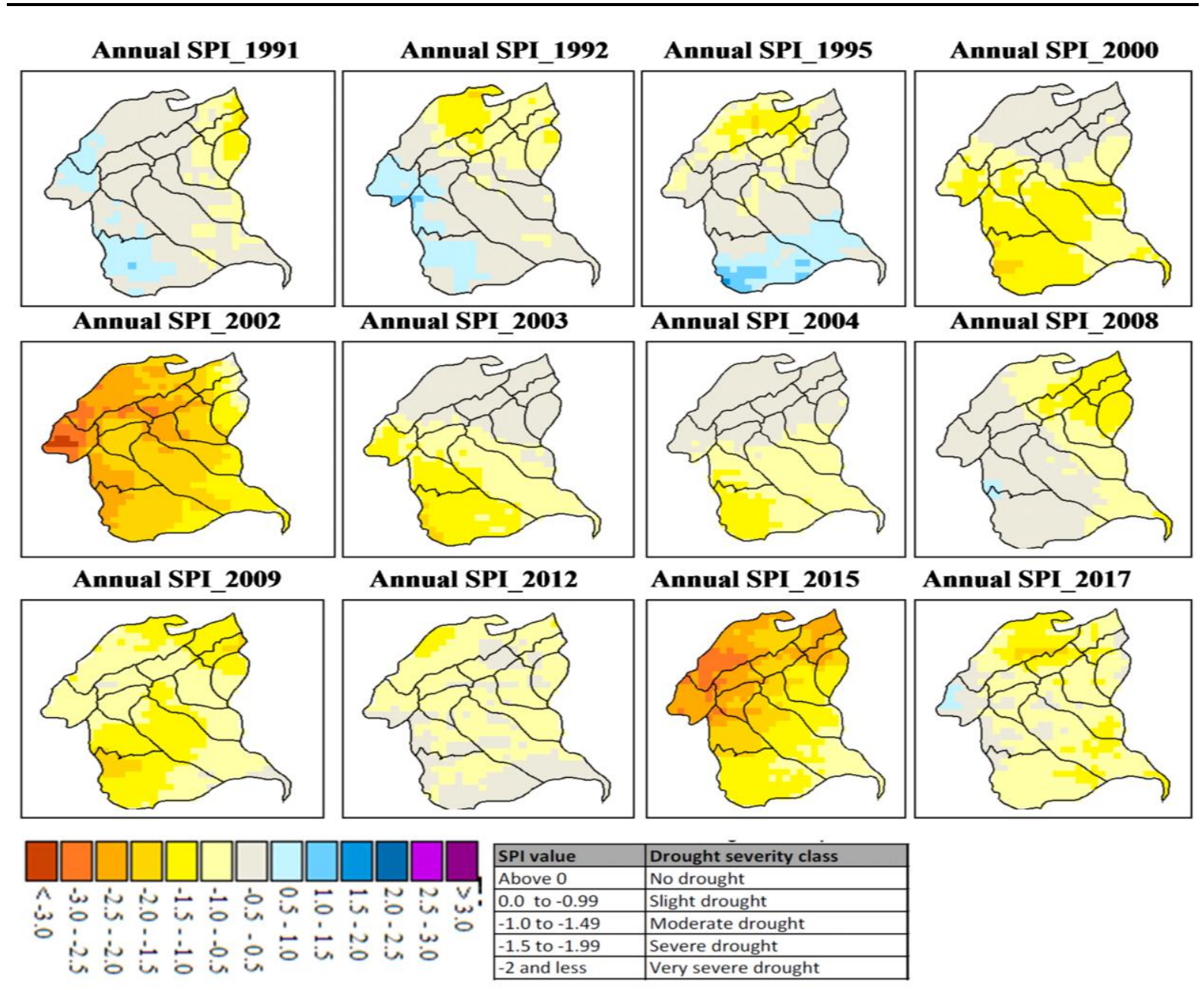

Figure5. Mapping spatial distribution of drought incidences

According to spatial analysis SPI 1-12 obtained (annual) from the GeoCLIM Tool, 20 Slight -Very severe drought events occurred in the period 1990-2018 in the province of West Hararge. The most important events were in the 2002, $2009 \& 2015$ 's, (all reached the very severe threshold); in the 1990, 1991, 1992, 1994, 1995, 1998, 1999, 2000, 2001, 2003, 2004, 2007, 2008, 2011, 2012, 2014 and 2017 areas of province were slight to severe threshold. In recent year frequent number of events, with greater SPI values, as can be seen in (Figure5).

6.4. Seasonal and Annual Drought Frequency from 1990 - 2003 and 2004 - 2018.

Table1.2 Strength of Drought

\begin{tabular}{|l|l|l|l|l|}
\hline Strength of Drought & Kiremt & Belg & Bega & Annual \\
\hline $\boldsymbol{m}-\boldsymbol{s}$ & $23.4 \%$ & $12.78 \%$ & $14.89 \%$ & $40 \%$ \\
\hline $\boldsymbol{s}$ & $2.12 \%$ & $10.64 \%$ & $10.64 \%$ & $45 \%$ \\
\hline $\boldsymbol{v}-\boldsymbol{s}$ & $12.76 \%$ & $8.51 \%$ & $2.12 \%$ & $15 \%$ \\
\hline
\end{tabular}

Key: $\boldsymbol{m}$-s means moderate to slight, $\mathbf{s}$ means slight, $v$-s means very severe

Table1.3 Probability of recurrence

\begin{tabular}{|l|l|l|l|}
\hline SPI & Category & No. of time in years & Severity of Events \\
$\mathbf{0}$ to $-\mathbf{0 . 9 9}$ & Slight & 10 & in 2yrs \\
\hline $\mathbf{- 1}$ to $\mathbf{- 1 . 4 9}$ & Moderate & 7 & 1 in 3yrs \\
$\mathbf{< - 2}$ & Very Severe (Extreme) & 3 & 1 in 7yrs \\
\hline Not occurred & No Drought events & 9 & ------ \\
\hline
\end{tabular}

Table1.4 Seasonal and Annual Drought Frequency from 1990 - 2018

\begin{tabular}{|l|l|l|l|l|l|l|l|l|}
\hline S.No. & Year & Annual & Season & Frequency & \multicolumn{2}{|l|}{ Remark } & \\
\cline { 5 - 8 } & & & & & Kiremt & Belg & Bega & Annual \\
\hline $\mathbf{1}$ & $\mathbf{1 9 9 0}$ & $\mathrm{H}$ & $\mathrm{K} \& \mathrm{~B}$ & 2 & $\mathrm{~m}-\mathrm{s}$ & No & m-s & No \\
\hline
\end{tabular}


Seasonal and Annual Meteorological Drought Frequency: Case Study West Hararge Province (Zone)

\begin{tabular}{|c|c|c|c|c|c|c|c|c|}
\hline $\begin{array}{l}2 \\
3 \\
\end{array}$ & $\begin{array}{l}1991 \\
1992 \\
\end{array}$ & $\begin{array}{l}\mathrm{H} \\
\mathrm{H}\end{array}$ & $\begin{array}{l}K \& B \\
K\end{array}$ & $\begin{array}{l}2 \\
1 \\
\end{array}$ & $\begin{array}{l}\mathrm{V}-\mathrm{s} \\
\mathrm{m}-\mathrm{s}\end{array}$ & $\begin{array}{l}\text { No } \\
\text { No }\end{array}$ & $\begin{array}{l}\text { m-s } \\
\text { No }\end{array}$ & $\begin{array}{l}\mathrm{S} \\
\mathrm{m}-\mathrm{s}\end{array}$ \\
\hline 4 & 1993 & $\mathrm{H}$ & $\mathrm{K}$ & 1 & V-S & No & No & No \\
\hline 5 & 1994 & $\mathrm{H}$ & $\mathrm{BL}$ & 1 & No & m-s & No & $\mathrm{S}$ \\
\hline 6 & 1995 & $\mathrm{H}$ & $K \& B$ & 2 & m-s & No & m-s & m-s \\
\hline $\begin{array}{l}7 \\
8\end{array}$ & $\begin{array}{l}1996 \\
1997\end{array}$ & $\begin{array}{l}\mathrm{NO} \\
\mathrm{H}\end{array}$ & $\begin{array}{l}\mathrm{NO} \\
\mathrm{K} \& \mathrm{BL}\end{array}$ & $\begin{array}{l}\text { No } \\
2\end{array}$ & $\begin{array}{l}\text { No } \\
\text { m-s }\end{array}$ & $\begin{array}{l}\text { No } \\
\text { S }\end{array}$ & $\begin{array}{l}\text { No } \\
\text { No }\end{array}$ & $\begin{array}{l}\text { No } \\
\text { No }\end{array}$ \\
\hline 9 & 1998 & $\mathrm{H}$ & K \& BL & 2 & $\mathrm{~m}-\mathrm{s}$ & $\mathrm{s}$ & No & $\mathrm{S}$ \\
\hline 10 & 1999 & $\mathrm{H}$ & $\mathrm{K} \& \mathrm{BL}$ & 2 & $\mathrm{~s}$ & m-s & No & $\mathrm{S}$ \\
\hline 11 & 2000 & $\mathrm{H}$ & $\mathrm{K} \& \mathrm{BL}$ & 2 & m-s & m-s & No & m-s \\
\hline 12 & 2001 & $\mathrm{H}$ & $\mathrm{B}$ & 1 & No & No & m-s & $\mathrm{S}$ \\
\hline $\begin{array}{l}13 \\
14\end{array}$ & $\begin{array}{l}2002 \\
2003\end{array}$ & $\begin{array}{l}\mathrm{H} \\
\mathrm{H}\end{array}$ & $\begin{array}{l}\mathrm{K} \& \mathrm{BL} \\
\mathrm{B} \& \mathrm{BL}\end{array}$ & $\begin{array}{l}2 \\
2\end{array}$ & $\begin{array}{l}\text { v-s } \\
\text { No }\end{array}$ & $\begin{array}{l}\text { v-s } \\
\text { m-s }\end{array}$ & $\begin{array}{l}\text { No } \\
\mathrm{S}\end{array}$ & $\begin{array}{l}\text { v-s } \\
\text { m-s }\end{array}$ \\
\hline 15 & 2004 & $\mathrm{H}$ & K \& BL & 2 & $\mathrm{~m}-\mathrm{s}$ & $\mathrm{s}$ & No & m-s \\
\hline 16 & 2005 & $\mathrm{H}$ & K \& BL & 2 & m-s & No & $\mathrm{s}$ & S \\
\hline 17 & 2006 & $\mathrm{NO}$ & $\mathrm{NO}$ & $\mathrm{No}$ & No & $\mathrm{No}$ & No & No \\
\hline 18 & 2007 & $\mathrm{H}$ & B \& BL & 2 & No & $\mathrm{S}$ & $\mathrm{s}$ & $\mathrm{S}$ \\
\hline 19 & 2008 & $\mathrm{H}$ & K \& BL & 2 & m-s & $\mathrm{V}-\mathrm{S}$ & No & m-s \\
\hline 20 & 2009 & $\mathrm{H}$ & K \& BL & 2 & $\mathrm{~V}-\mathrm{S}$ & m-s & No & $\mathrm{V}-\mathrm{S}$ \\
\hline 21 & 2010 & $\mathrm{H}$ & $\mathrm{B}$ & 1 & No & $\mathrm{No}$ & $\mathrm{V}-\mathrm{S}$ & No \\
\hline 22 & 2011 & $\mathrm{H}$ & B \& BL & 2 & No & m-s & m-s & $\mathrm{S}$ \\
\hline 23 & 2012 & $\mathrm{H}$ & $\mathrm{B} \& \mathrm{BL}$ & 2 & No & $\mathrm{V}-\mathrm{S}$ & m-s & $\mathrm{S}$ \\
\hline 24 & 2013 & NO & $\mathrm{NO}$ & No & No & No & No & No \\
\hline 25 & 2014 & $\mathrm{H}$ & $\mathrm{K}$ & 1 & m-s & No & No & No \\
\hline 26 & 2015 & $\mathrm{H}$ & $\mathrm{K}, \mathrm{B} \& \mathrm{BL}$ & 3 & $\mathrm{~V}-\mathrm{S}$ & $\mathrm{V}-\mathrm{s}$ & $\mathrm{s}$ & $\mathrm{V}-\mathrm{s}$ \\
\hline 27 & 2016 & $\mathrm{H}$ & $\mathrm{K}$ & 1 & $\mathrm{~m}-\mathrm{s}$ & No & $\mathrm{s}$ & No \\
\hline 28 & 2017 & $\mathrm{H}$ & B \& BL & 2 & No & $\mathrm{s}$ & m-s & m-s \\
\hline 29 & 2018 & $\mathrm{H}$ & $\mathrm{K}$ & 1 & $\mathrm{~m}-\mathrm{s}$ & No & No & No \\
\hline
\end{tabular}

Key: $\boldsymbol{K}$ means Kiremt Season, B means Bega Season and BL means Belg Season, $\boldsymbol{H}$ means Meteorological Drought Events

Table 1.5 Seasonal and Annual Drought Frequency from 1990 - 2003

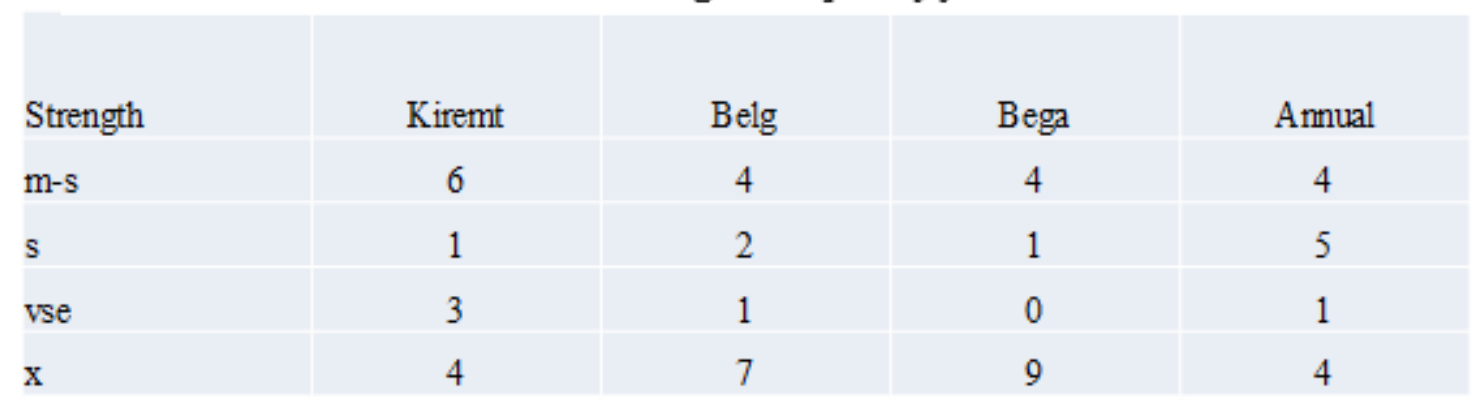

Sea sonal and Annual Meteorological drought Frequency from 1990-2003

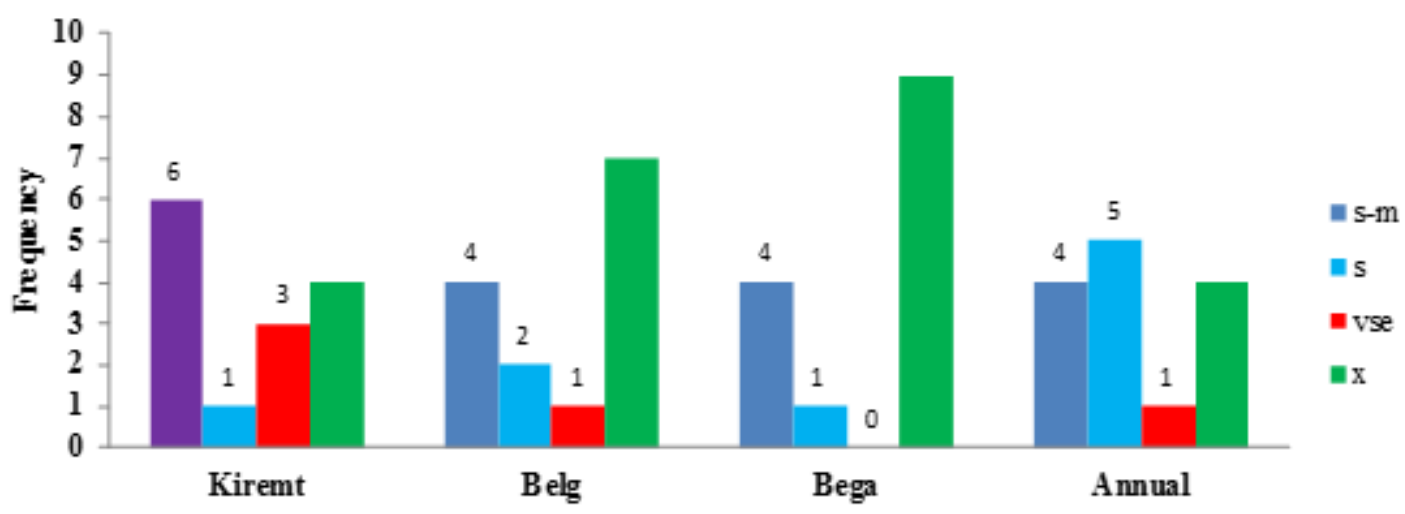

Graph 1.1 Seasonal and Annual Drought Frequency from 1990 - 2003 


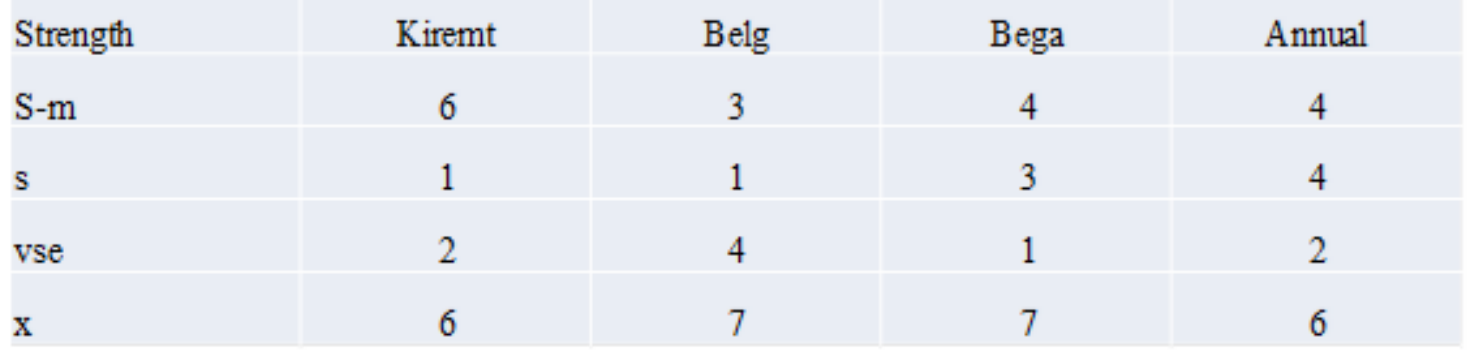

Table 1.6 Seasonal and Annual Drought Frequency from 2004 - 2018

Sea sonal and Annual M eteo ro logicalD rought F requency from 2004-2018

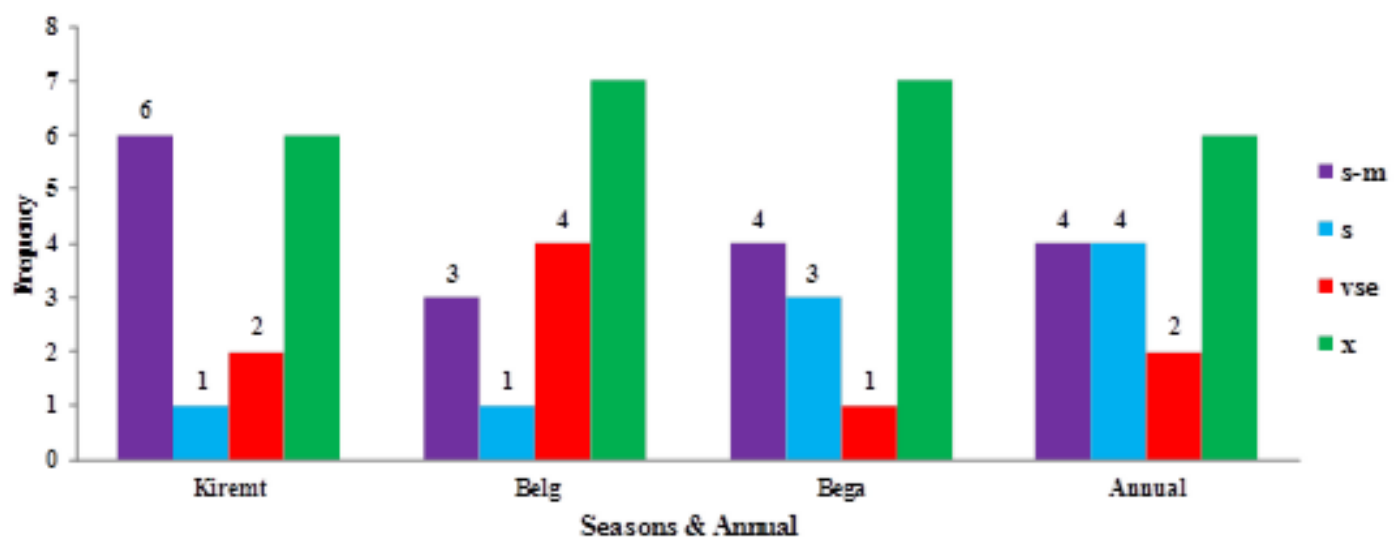

Graph 1.2 Seasonal and Annual Drought Frequency from 2004 - 2018

\section{CONCLUSION}

In this study, a brief Meteorological drought event analysis was presented using GeoCLIM Tool. It is a very important tool for quantifying drought and comparing its characteristics over time and space. We used GeoCLIM, in this study, to examine the magnitude and frequency. Here, Meteorological drought occurrences and frequency were analyzed at seasonal and annual (4-12-month) time scales (Figure 5 and Graph1.1, $1.2 \&$ Table $1.2 \& 1.4$ ). Though almost parts of province in the study region suffer from Meteorological drought frequency, it is important to consider that all parts of province did not experience well-defined Meteorological drought frequency and Magnitude during the same periods. In other words, temporal distribution and frequency of droughts varied markedly among each parts of province. Very severe droughts were more pronounced in areas where their altitude is above 1200-3080m asl (Figure5). Areas in western and Central of the study region were exposed to high frequency of severe and very severe droughts at annual time scale (Figure5).Some of the drought years in the study province identified by this GeoCLIM Tool analysis were among the worst drought years in the history of Ethiopia. The year 2002, 2009 \& 2015, for example, was the most drastic and distinct-wide drought episode. Almost all province experienced slight to very severe magnitude and frequent meteorological drought at seasonal and annual timescales in the specified year. During the study periods annual drought event were $68.97 \%$ while no drought event were $31.03 \%$. The seasonal drought contribution to the study area is Kiremt (40.42\%), Belg (31.92\%) and Bega (27.66\%). Annual drought tendency were very severe, slight and moderate drought with the magnitude of $15 \%, 50 \%$ and $35 \%$ respectively. Probability of recurrence on the category were slight, moderate and very severe drought on number of time in years 10, 7 and 3 and the magnitudes of severity of events 2 in $2 \mathrm{yrs}, 1$ in 3yrs and 1 in 7yrs respectively. The study identify that seasonal meteorological drought strength ranges from slight to very severe magnitude during study period. More Meteorological drought frequency occurred during Kiremt season (Graph1.1\&1.2, Table1.2).

In general, the entire study area can be considered as frequently meteorological drought prone area. Increasing tendencies and frequency of drought were observed during recent year. The finding shows 
that in the first decade (1990-1999) the annual magnitude of drought tendency were slight to moderate, whereas in the second decade (2000-2009) were under slight ,moderate and very severe and at the third decade (2010-2018) were under slight, moderate, and very severe categories. The seasonal magnitude of drought tendency increase both kiremt and belg during the second decade (1999-2009) (Figure 5, Graph1.1, 1.2 \& Table 1.2, 1.3, 1.4, 1.5 and 1.6), and this shows that there is an increasing of drought frequency and tendency. The patterns of drought events in the study area are highly localized

\section{RECOMMENDATIONS}

A comparison of SPI index magnitude of an area is useful for drought risk mapping. Hence, this drought risk map could play a vital role in the decision-making process for Meteorological drought monitoring strategies and policies.

Special attention (local-scale planning) should be given, while decision makers plan to effectively manage meteorological drought frequency. The findings of this study have implications for meteorological drought frequency management, early warning system, preparedness and contingency planning and climate change adaptation. In real sense, drought is a climatic event that cannot be prevented very easily, but interventions and preparedness to drought can help to cope with drought by developing more resilient ecosystems, improving resilience to recover from drought and taking various adaptation strategies like using weather information, water harvesting, making irrigation system more efficient and a geographical shift of agricultural system.

The study area which is East Hararge as shown above result, to be recommended to study drought frequency and its magnitude in future as Regional or Woreda level.

\section{REFERENCES}

[1] Hammouri and Naqa, 2007: Drought Assessment Using GIS and Remote Sensing in Amman-Zarqa Basin, Jordan Journal of Civil Engineering, Volume 1, No. 2, 2007

[2] Shiau, J.T. : Fitting Drought Duration and Severity with Two-Dimensional Copulas. Water Resour Manage 20, 795-815 (2006). https://doi.org/10.1007/s11269-005-9008-9

[3] (Wang, 2005), Agricultural drought in a future climate: Results from 15 global climate models participating in the IPCC 4th assessment

[4] Reichstein et al., 2002: December 2018 In book: Climate Change and Water Resources in India (pp.117129)

[5] Publisher: Ministry of Environment, Forest and Climate Change (MoEF\&CC), Government of India

[6] Bardsley et al., 1984. Evaluation of trends and multivariate frequency analysis of droughts in three meteorological subdivisions of western India

[7] Dracup Et Al., 1980: The Relationship of Drought Frequency and Duration to time scales period Malaet al., 201) :drought frequency

[8] Linsleyet Al., 1975. : Drought severity of the indicator for the basin. Understanding The Drought Phenomenon: The Role Of Definitions (Sruthi And Aslam, 2015).

[9] Mala et al., 2014. : Assessing drought conditions through temporal pattern, spatial characteristic and operational accuracy indicated by SPI and SPEI: case analysis for Peninsular Malaysia Guttman, 1999; WMO, 2012: Standardized Precipitation Index User Guide

[10] Wilhite, D.A.; Glantz, M.H. Understanding the Drought Phenomenon: The Role of Definitions. Water Int.

[11]Bewket, W. and Conway, D. (2007), "A note on the temporal and spatial variability of rainfall in the drought-prone Amhara region of Ethiopia", The International Journal of Climatology, Vol. 27, pp.14671477, doi: 10.1002/joc.1481.Segele and Lumb (2005),

[12] Degefu, W. (1987), "Some aspects of meteorological drought in Ethiopia", in Glantz, M.H. (Ed.), Drought and Hunger in Africa: Denying Famine a Future, Press Syndicate of the University of Cambridge, Cambridge, MA, pp. 223-236.

[13]Degefu, M.A. and Bewket, W. (2013), "Trends and spatial patterns of drought incidence in the omoghibe river basin, Ethiopia”, GeografiskaAnnaler: Series A, Physical Geography, doi: 10.1111/geoa.12080.

[14] Edossa, D.C., Babel, M.S. and Gupta, A.D. (2010), "Drought analysis in the Awash river basin, Ethiopia", Water Resources Management, Vol. 24 No. 7, pp. 1441-1460, doi: 10.1007/s11269-009-9508-0. 
[15] Wilhite, D.A. (1993), "Drought assessment, management, and planning: theory and case studies", Natural Resource Management and Policy Series, Vol. 2, Kluwer.

[16] Wilhite, D.A. and Glantz, M.H. (1985), "Understanding: the drought phenomenon: the role of definitions", Water International, Vol. 10 No. 3, pp. 111-120.

[17] Wilhite, D. A. (2000), Drought as a natural hazard: Concepts and definitions, in Droughts: A Global Assessment, edited by D. A. Wilhite, pp. 3-18, Routledge, London. Eighth Conference on Applied Climatology, 17-22 January 1993, Anaheim, California

[18] Rathore. (2009). M.S. State Level analysis of Drought Policies and Impacts in Rajasthan, India. Working Paper 93, Drought Series, Paper-6.

[19] Panu, U.S., Sharma T. C. (2002). Challenges in drought research: some perspectives and future directions, Hydrological Sciences Journal, 47:S1, S19-S30

Citation: Tilahun Dandesa, et.al., "Seasonal and Annual Meteorological Drought Frequency: Case Study West Hararge Province (Zone)", International Journal of Research in Environmental Science (IJRES), vol. 7, no. 1, pp. 1-10, 2021. Available: DOI: http://dx.doi.org/ 10.20431 /2454-9444.0701001

Copyright: (C) 2021 Authors. This is an open-access article distributed under the terms of the Creative Commons Attribution License, which permits unrestricted use, distribution, and reproduction in any medium, provided the original author and source are credited. 